\title{
Toughness of Polymer Modified Steel Fiber Reinforced Concrete
}

\author{
U. B. Kalwane1, Y. M. Ghugal'2, A. G. Dahake ${ }^{3}$ \\ ${ }^{1}$ Department of Civil Engineering, Shreeyash College of Engineering and Technology, Aurangabad, India \\ ${ }^{2}$ Department of Applied Mechanics, Government College of Engineering, Karad, India \\ ${ }^{3}$ Department of Civil Engineering, Marathwada Institute of Technology, Aurangabad, India \\ Email:kalwane62@gmail.com, ghugal@rediffmail.com, ajaydahake@gmail.com
}

Received 6 February 2016; accepted 22 February 2016; published 25 February 2016

Copyright (C) 2016 by authors and Scientific Research Publishing Inc.

This work is licensed under the Creative Commons Attribution International License (CC BY).

http://creativecommons.org/licenses/by/4.0/

(c) () Open Access

\begin{abstract}
An experimental investigation is carried out to study the toughness of polymer modified steel fiber reinforced concrete. Volume fraction of steel fibers is varied from $0 \%$ to $7 \%$ at the interval of $1 \%$ by weight of cement. 15\% SBR latex polymer was used by weight of cement. Cubes of size $150 \times$ $150 \times 150 \mathrm{~mm}$ for compressive strength, prism specimens of size $150 \mathrm{~mm} \times 150 \mathrm{~mm} \times 700 \mathrm{~mm}$ for flexure strength and, specimen of size $150 \times 150 \times 150 \mathrm{~mm}$ with $16 \mathrm{~mm}$ diameter tor steel bar of length $650 \mathrm{~mm}$ embedded in concrete cube at the center for bond test were prepared. Various specimens were tested after 28 days of curing. Area under curve (toughness) is measured and mentioned in this work.
\end{abstract}

\section{Keywords}

Toughness, Steel Fiber Reinforced Concrete, Polymer Modified Steel Fiber Reinforced Concrete

\section{Introduction}

Concrete is one of the most promising construction materials with regards to its strength, high serviceability, structural stability and relative low cost. To achieve impressive gains in safety, functionality and economy materials technology have been enabled, and functionality of structure is built to serve the common needs of society. There are clear indications that the use of fibers and polymer in concrete will increasingly continue to be the preferred choice for many repair and rehabilitation projects involving construction of bridges, industrial floors, airport pavements, overlays, high rise buildings, TV towers, parking garages, offshore structures, historic monuments etc.

The advancement of the building industry is associated with continuous research, development and design of 
new and improved materials and construction of structures. The construction of mega structures requires materials with increasingly improved properties; particularly toughness is focused on the inclusion of additives, polymeric admixtures, and fibers to improve certain physical and mechanical properties, though keeping its strength, low cost and capacity to fill almost any shape.

Toughness is expressed as a ratio of the amount of energy required to deflect the beam to a specified deflection expressed as multiples of first crack energy (deflection); i.e. toughness is the energy absorption capacity of a composite. Toughness is an important attribute of fiber reinforced concrete. It is one of the important mechanical performance parameters to be insured in the design of special applications, such as, earthquake resistant structures, impact resistant structures and tunnel linings.

Toughness plays a vital role in reinforced cement concrete structures. Fiber reinforcement has been shown to improve the toughness, ductility, flexural strength and bond between steel and concrete of cementitious materials, to reduce shrinkage cracking and permeability and to enhance fatigue and impact resistance. Fiber reinforcement is used to improve the ductility of cementitious composites [1].

Balaguru and Najm [2] have conducted experimental investigation of high performance fiber reinforced concrete with fiber volume fractions up to $3.75 \%$. Test results showed that the increase in the fiber volume fraction to $3.75 \%$ resulted in an approximately $100 \%$ increase in material toughness compared with conventional steel fiber reinforced concrete. It is also reported that the fiber reinforced concrete with hooked steel fibers had the highest toughness compared with straight fibers and polypropylene microfibers.

Control of cracking automatically improves the mechanical properties of the composite material. The most significant property of steel fiber reinforced concrete is its post-cracking strength that can impart the ability to absorb large amounts of energy before collapse. The efficiency of the fiber reinforcement of the matrix depends on the geometry, size, type, volume and dispersion of the fibers in concrete [3].

Inclusion of fibers in concrete improves the toughness, structural ductility, high-temperature, fire sensitivity, and impacts fatigue strength and strength in tension. It is reported that the hooked steel fibers have the highest toughness compared with straight, deformed and corrugated steel fibers [3]-[5].

Banthia and Bindiganavile [6] have carried out the study on fiber reinforced shotcrete and reported that the use of fiber reinforcement can provide high post-cracking flexural toughness. Topeu and Canbaz [7] studied the effect of different fibers on the mechanical properties of concrete containing fly ash. It is reported that the addition of fibers provides better performance for the concrete, while fly ash in the mixture may adjust the workability and strength losses caused by fibers and improve strength gain.

Mirsayah and Banthiya [8] have investigated the shear behavior of fiber reinforced concrete using fibers with flattened ends and a circular cross section and a crimped geometry with crescent cross section type fibers. They reported that both fibers provided significant improvements in shear strength as well as shear toughness and these improvements were greater at higher fiber dosage rates.

Nehdi and Landanchuk [9] have reported that fibers can have rheological and mechanical synergistic effects and that optimized fiber combinations can better increase toughness and flexural strength.

One of the most important properties of steel fiber concrete is its ability to transfer stresses across a cracked section. This ability is mostly translated into a toughness parameter, which is a measure for the energy consumed during a bending. It has shown that there is a high degree of proportionality between the toughness and the number of effective fibers that are counted in the cracked section [10].

Altun et al. [11] have reported that due to the addition of steel fibers, crack formation, crack size, and crack propagation in beams against bending moments are significantly reduced with significant improvement in the toughness. Taylor et al. [12] have studied toughness characterization of fiber-reinforced concrete.

In this study toughness characteristics of steel fiber reinforced concrete modified with SBR latex polymer are investigated. Toughness results of present concrete composite under compression, flexure and bond with varying fiber volume fraction are reported and discussed.

\section{Experimental Programme}

Experimental work was aimed to study the effect of polymer modification along with hooked steel fibers especially on toughness of concrete and its feasibility in the actual field of construction for considering flexural strength, compressive strength, pull-out test of polymer modified high strength and unmodified concrete. 


\subsection{Materials Used and Tests Performed}

For preparation of steel fiber reinforced concrete (SFRC) and polymer modified steel fiber reinforced concrete (PMSFRC), materials used were cement, fine aggregate, coarse aggregate $(20 \mathrm{~mm})$, coarse aggregate $(10 \mathrm{~mm})$, hooked end steel fibers, polymer latex, super plasticizer and water. The cement used in the present work was 53 grade ordinary Portland cement (OPC) conforming to IS: 12269-1987, the fineness moduli of fine and coarse aggregates were 2.872 and 6.97, respectively. High tensile steel fibers with hooked ends were used. They had hooked ends and were collated into clips of about 10 individual fibers using water soluble adhesive as shown in Figure 1. The collation reduces the tendency for balling of fibers during the mixing process. The adhesive dissolved in the mixing water in about one minute, facilitating the distribution of individual fibers. A hooked end which slowly deforms during pull-out is generally considered as the best form of anchorage.

Physical properties of fibers used for the experimental work are shown in Table 1.

Styrene butadiene rubber (SBR) latex is used as a polymer. This polymer is available in liquid form containing $40 \%$ solids and $60 \%$ water. The water contained in the polymer has included in the total water content of the mix i.e. reduce the amount of water contained in polymer from the quantity of w/c ratio while adding the water to the concrete mix. This is a non-epoxy thermosetting polymer. Properties of this polymer are shown in Table 2.

Roff Super plast 320 have been used as super plasticizer to improve the workability of concrete. Dosage used in this experimental work was $1.75 \%$ by weight of cement. This super plasticizer is added to mixing water first and then this mixture is added to the dry mix concrete.

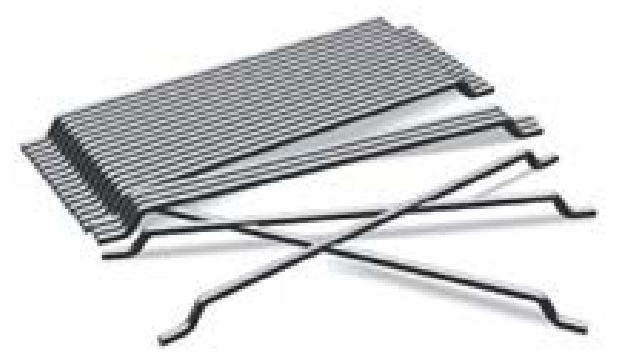

Figure 1. Hooked end steel fibers.

Table 1. Physical properties of hooked end steel fiber.

\begin{tabular}{cc}
\hline Description & Value \\
\hline Length of fiber $(l)$ & $60 \mathrm{~mm}$ \\
Thickness (diameter) of fiber $(d)$ & $0.75 \mathrm{~mm}$ \\
Aspect ratio $(l / d)$ & 80 \\
Tensile strength & $2000 \mathrm{MPa}$ \\
Specific gravity & 7.8 \\
Modulus of elasticity & $200 \mathrm{Gpa}$ \\
\hline
\end{tabular}

Table 2. Properties of polymer.

\begin{tabular}{cc}
\hline Property & Description \\
\hline Polymer system & Polymer Latex additive (Monobond) \\
Type & Polymer latex \\
Base & Milky white \\
Appearance & Slow \\
Setting characteristics & 15 sec \\
Viscosity at 270c $( \pm 2)$ & 1.08 \\
Specific gravity at 270c $( \pm 2)$ & 10.40 \\
pH &
\end{tabular}




\subsection{Tests Performed on Hardened Concrete Specimens}

\section{Compression Test}

The compression test was performed to find out compressive strength of polymer modified steel fiber reinforced concrete on test specimens cubical in shape of size $150 \mathrm{~mm} \times 150 \mathrm{~mm} \times 150 \mathrm{~mm}$, confirming to IS: 10086-1982. Compression testing machine of capacity $3000 \mathrm{kN}$ was used. The schematic test setup is shown in Figure 2 and compression test of concrete cube in progress is shown in Figure 3.

The compressive strength of the specimen is calculated by dividing the maximum load applied to the specimen during the test by the cross sectional area, i.e. by using the formula

$$
f_{c u}=\frac{P_{c}}{A}
$$

where $f_{c u}=$ Compressive strength of concrete in $\mathrm{MPa}$;

$P_{c}=$ Maximum applied load in $\mathrm{kN}$;

$A=$ Cross sectional area in $\mathrm{mm}^{2}$.

\section{Flexure Test}

To find out flexural strength of concrete, prism specimens of size $150 \mathrm{~mm} \times 150 \mathrm{~mm} \times 700 \mathrm{~mm}$ were used. The arrangement for loading of flexure test specimen is shown in Figure 4. The prism specimen shall be placed in the machine in such a manner that the load shall be applied to the uppermost surface as cast in the mould, along two lines spaced $200 \mathrm{~mm}$ apart i.e. two point load. The axis of the specimen shall be carefully aligned with the axis of the loading device. The load was applied without shock and increased continuously at the rate of $400 \mathrm{~kg} / \mathrm{min}$. The appearance of the fractured faces of concrete and any unusual features in the type of failure was noted. Flexure test on concrete beam under progress is shown in Figure 5.

The flexural strength of the specimen $\left(f_{b}\right)$ is calculated by using following expression:

$$
f_{b}=\frac{P a}{b d^{2}}
$$

where $P$ = maximum applied load to the specimen in $\mathrm{kN}$;

$a=$ span of the beam in $\mathrm{mm}$;

$b=$ width of the beam specimen in $\mathrm{mm}$;

$d=$ depth of the beam specimen in $\mathrm{mm}$.

\section{Pullout Test (Bond Strength Test)}

Pullout test was performed to find out bond strength of concrete. The specimens were cast according to ASTM standard C234-91a. Concrete cube of size $150 \mathrm{~mm} \times 150 \mathrm{~mm} \times 150 \mathrm{~mm}$ with a $16 \mathrm{~mm}$ diameter tor steel bar embedded $150 \mathrm{~mm}$ in concrete cube as shown in Figure 6 was used as test specimen. The verticality of 16 mm embedded tor steel rod was ensured by supporting it till the concrete hardens.

The pullout test was carried out at 28 days using Universal Testing Machine (UTM). The specimen was held between upper and middle cross-head. The rod was gripped in upper cross-head and cube was held below middle cross-head as shown in Figure 7.

The tensile load was applied on steel bar for pullout purpose. The loads and slips were recorded at every 400 $\mathrm{Kg}$ interval till failure of specimen. The maximum pull-out force is recorded in the test at bond failure. The deformations (slips) were recorded with sensitive dial gauge of least count $0.01 \mathrm{~mm}$. The maximum pull force, $P$ and corresponding slip, $\Delta$ were used to calculate the pull-out work done $(P \times \Delta)$ from this test. The bond strength is calculated by using the equation

$$
\tau_{b d}=\frac{P}{\pi d l}
$$

where $\tau_{b d}=$ bond strength of concrete in MPa;

$P=$ pull-out force in $\mathrm{kN}$;

$d=$ diameter of steel bar embedded in concrete cube in $\mathrm{mm}$;

$l=$ length of the bar embedded in concrete in $\mathrm{mm}$. 


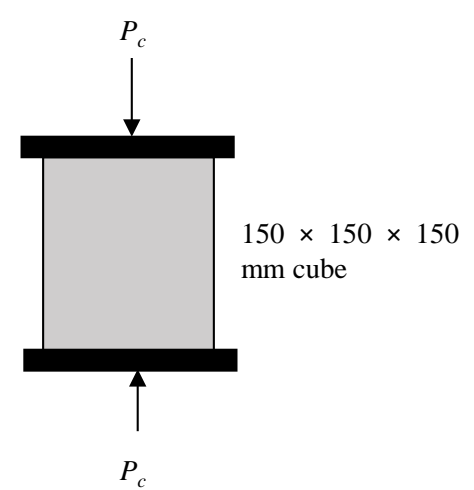

Figure 2. Compression test setup.

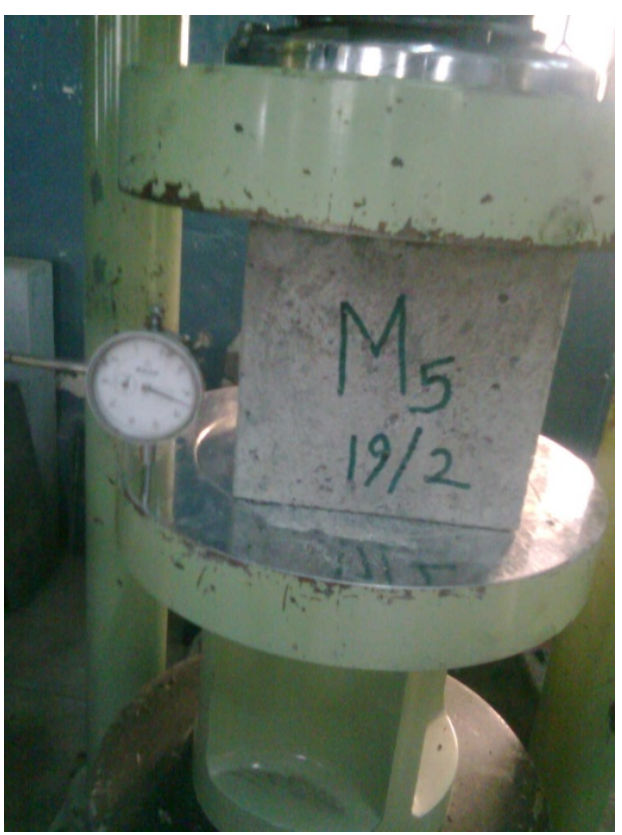

Figure 3. Compression test on concrete cube in progress.

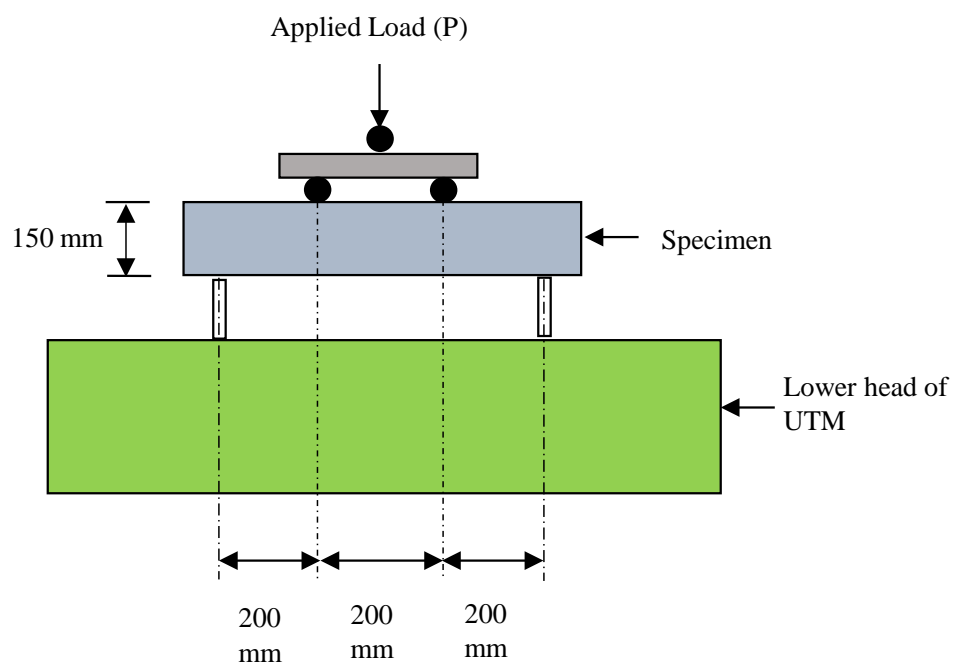

Figure 4. Loading arrangement for flexure test. 


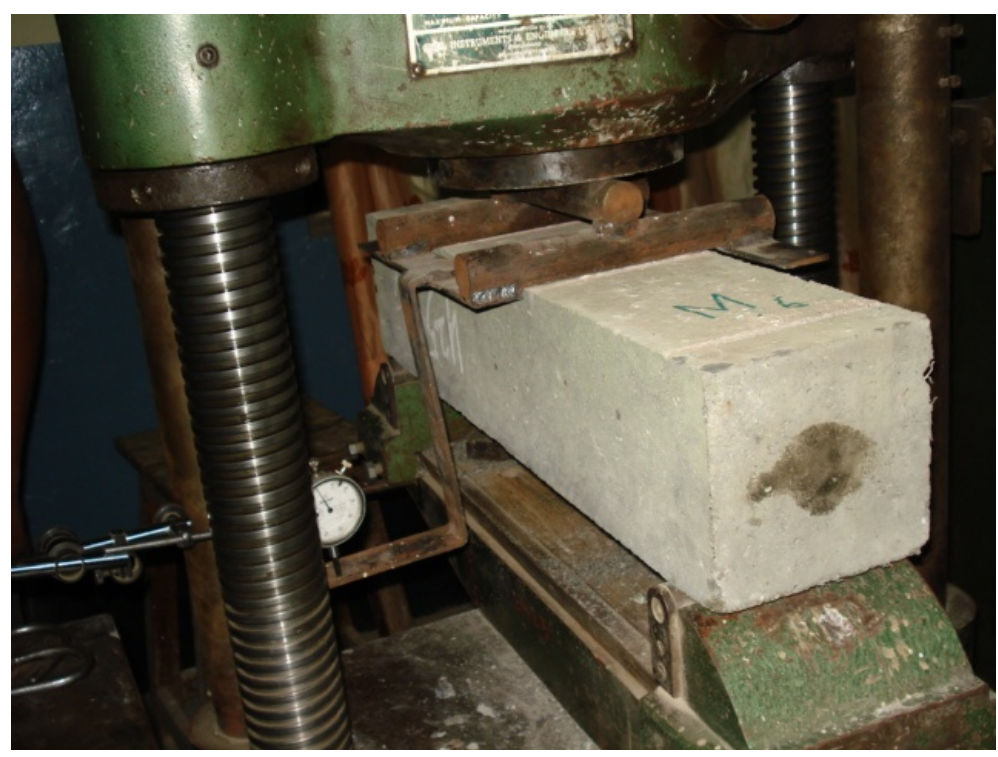

Figure 5. Flexure test on concrete beam under progress.

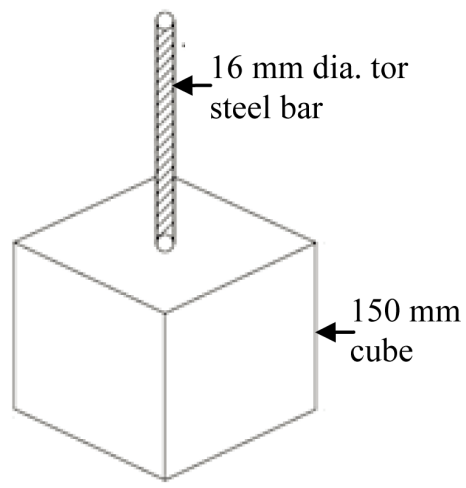

Figure 6. Pullout test specimen.

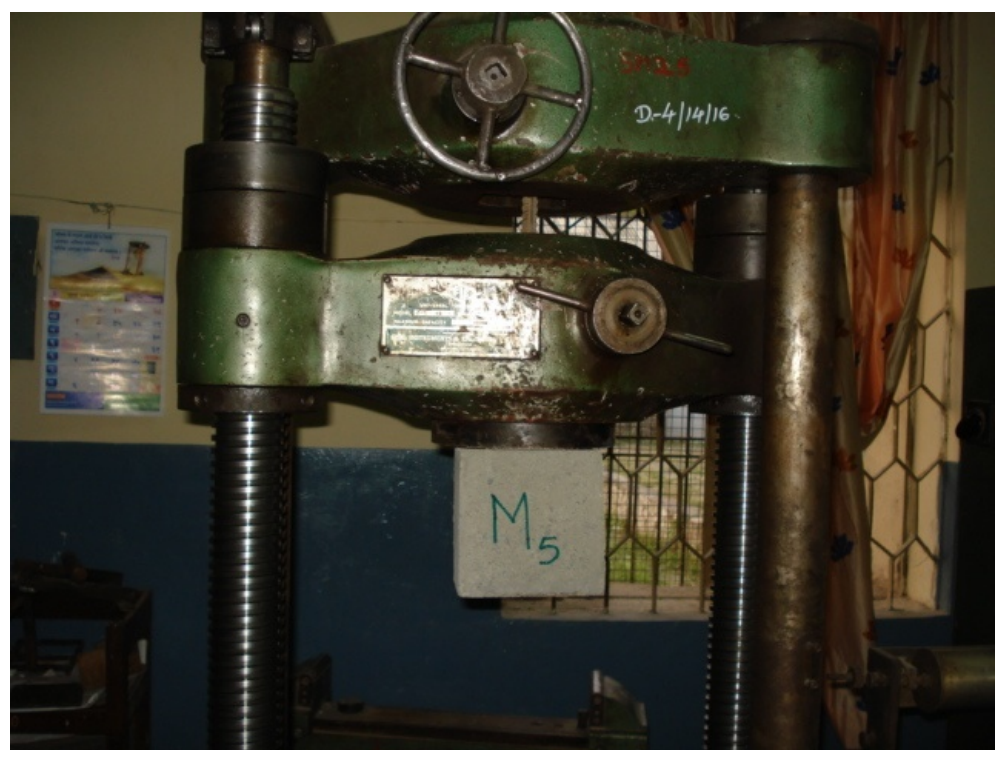

Figure 7. Pullout test under progress. 


\section{Results and Discussion}

In the present work, to find out the toughness of fiber reinforced concrete compression test, flexural test and pull-out test were conducted on cubes, beams and pull-out specimens and results of various toughnesses in kN$\mathrm{mm}$ are presented. The toughness is calculated as an area under the stress-strain curve for compression, loaddeflection curve for flexure and pull-out load-slip curve for bond strength.

Area under stress-strain curve for compression, load-deflection curve for flexure and pullout force-slip curve in bond strength test are calculated from Figures 8-12 and presented in Table 3. Expressions for toughness for compression, flexure and bond at 28 days in $3^{\text {rd }}$ degree polynomial in terms of fiber content $\left(V_{f}\right)$ are mentioned in Table 4 obtained from Figures 13-15.

It is observed from Table 3 that the toughness is found to be strength dependent. In case of SFRC maximum toughness values under compression, flexure and bond are observed at 7\%, $4 \%$ and $3 \%$ respectively and in case of PMSFRC they are observed at $1 \%, 7 \%$ and $3 \%$ respectively. Only in case of bond toughness increasing trend is observed up to $3 \%$ of fiber content. In other cases no specific trend is seen. The variations in toughnesses with respect to their strengths may be attributed to the synergistic influence of fiber and polymer and needs further investigations.

Table 3. Toughness for compression, flexure and bond test of SFRC and PMSFRC.

\begin{tabular}{cccccc}
\hline \multirow{2}{*}{$\begin{array}{c}\text { Mix } \\
\text { designation }\end{array}$} & $\begin{array}{c}\text { Fiber content } \\
\left(V_{f}\right) \%\end{array}$ & $\begin{array}{c}\text { Polymer } \\
\text { content }\end{array}$ & \multicolumn{3}{c}{ Toughness in kN-mm } \\
\cline { 4 - 5 } $\mathrm{M}_{0}$ & 0 & & 1657.91 & 38.72 & 527.10 \\
$\mathrm{M}_{1}$ & 1 & & 1596.28 & 133.14 & 1595.42 \\
$\mathrm{M}_{2}$ & 2 & & 2672.20 & 278.91 & 2319.24 \\
$\mathrm{M}_{3}$ & 3 & \multirow{2}{*}{ Compression } & Flexure & Bond \\
$\mathrm{M}_{4}$ & 4 & 2251.01 & 306.79 & 2526.75 \\
$\mathrm{M}_{5}$ & 5 & & 2626.53 & 331.09 & 2157.82 \\
$\mathrm{M}_{6}$ & 6 & & 2527.67 & 274.47 & 2305.58 \\
$\mathrm{M}_{7}$ & 7 & & 2740.57 & 205.71 & 1807.82 \\
$\mathrm{M}_{8}$ & 0 & & 2799.06 & 278.93 & 1938.32 \\
$\mathrm{M}_{9}$ & 1 & & 2109.29 & 72.28 & 286.51 \\
$\mathrm{M}_{10}$ & 2 & & 2189.78 & 249.83 & 1380.13 \\
$\mathrm{M}_{11}$ & 3 & 1879.56 & 307.33 & 2049.45 \\
$\mathrm{M}_{12}$ & 4 & $15 \%$ & 2093.45 & 292.31 & 2090.69 \\
$\mathrm{M}_{13}$ & 5 & & 2179.18 & 288.85 & 2089.36 \\
$\mathrm{M}_{14}$ & 6 & & 2079.04 & 341.64 & 1826.79 \\
$\mathrm{M}_{15}$ & 7 & & 1636.29 & 321.74 & 1547.47 \\
\hline & & & 1578.52 & 353.05 & 1859.00 \\
\hline
\end{tabular}

Table 4. Expressions for toughnesses at 28 days in terms of fiber content $\left(V_{f}\right)$.

\begin{tabular}{cc}
\hline Toughness $(\mathrm{kN}-\mathrm{mm})$ & SFRC \\
\hline Compression & $T_{c}=5.433 V_{f}^{3}-83.55 V_{f}^{2}+497.4 V_{f}+1547.6$ \\
Flexure & $T_{f}=3.224 V_{f}^{3}-47.46 V_{f}^{2}+208.4 V_{f}+16.18$ \\
Bond & $T_{b}=25.3 V_{f}^{3}-364.6 V_{f}^{2}+1514 . V_{f}+499.65$ \\
Toughness $(\mathrm{kN}-\mathrm{mm})$ & PMSFRC \\
Compression & $T_{c}=-6.569 V_{f}^{3}+47.56 V_{f}^{2}-99.76 V_{f}+2128.8$ \\
Flexure & $T_{f}=3.474 V_{f}^{3}-44.24 V_{f}^{2}+178.7 V_{f}+86.549$ \\
Bond & $T_{b}=29.63 V_{f}^{3}-397.9 V_{f}^{2}+1555 V_{f}+256.83$ \\
\hline
\end{tabular}




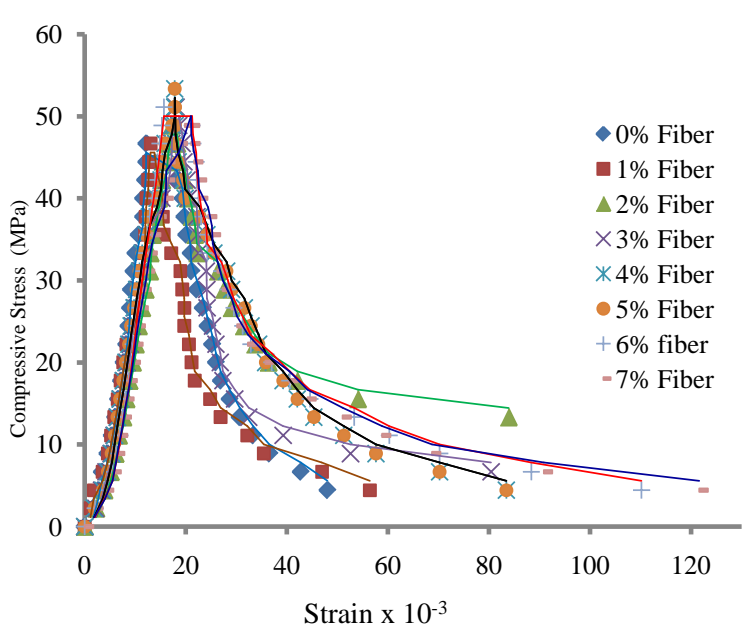

Figure 8. Variation of compressive strength with respect to strain (SFRC).

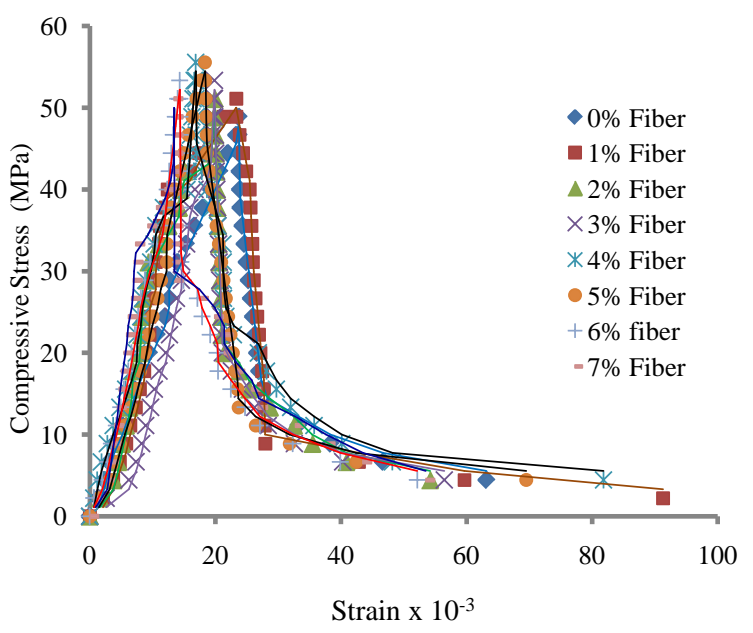

Figure 9. Variation of compressive strength with respect to strain (PMSFRC).

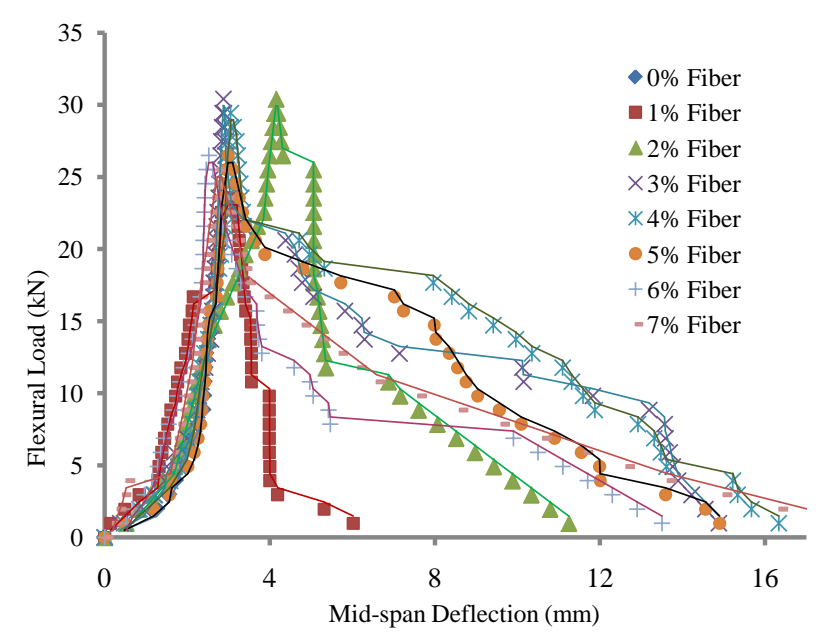

Figure 10. Variation of flexural load with respect to mid span deflection (SFRC). 


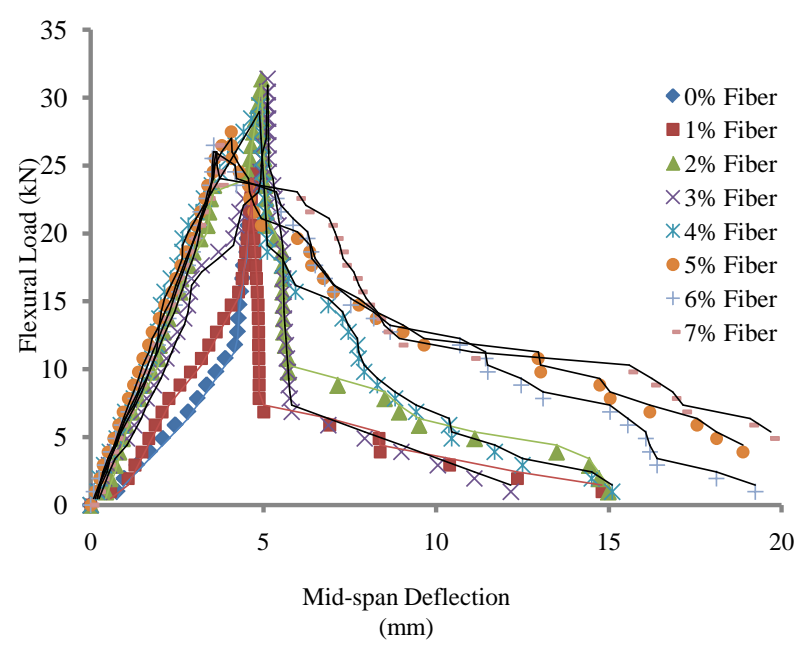

Figure 11. Variation of flexural load with respect to mid span deflection (PMSFRC).

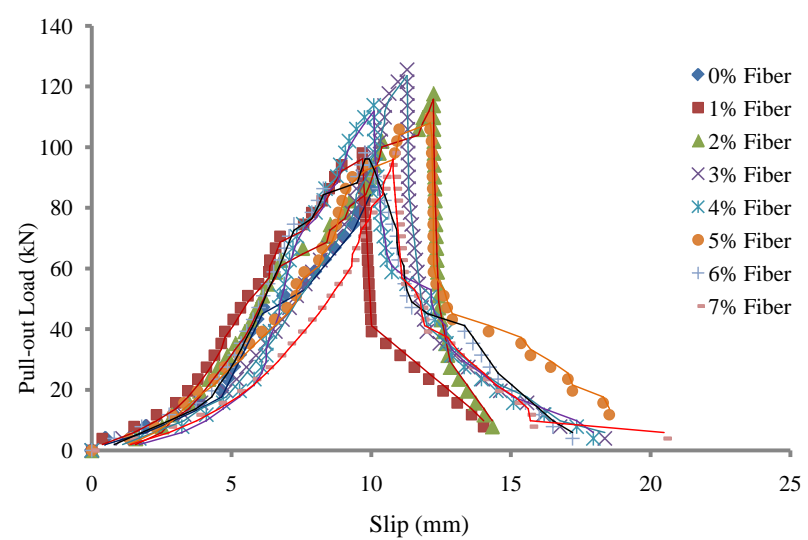

Figure 12. Variation of pull out load with respect to slip (SFRC).

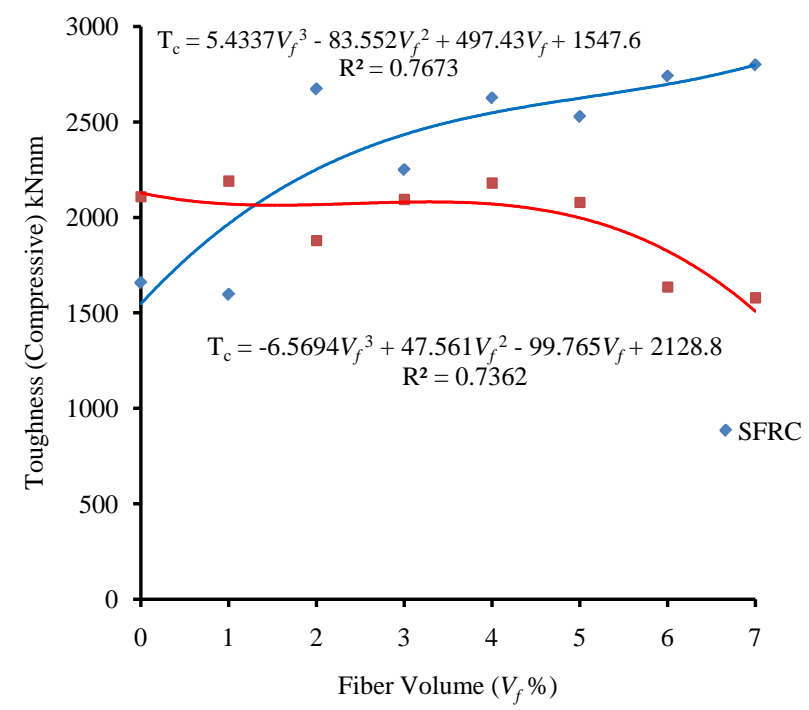

Figure 13. Variation of compression toughness $\left(T_{c}\right)$ with respect to fiber content $\left(V_{f}\right)$. 


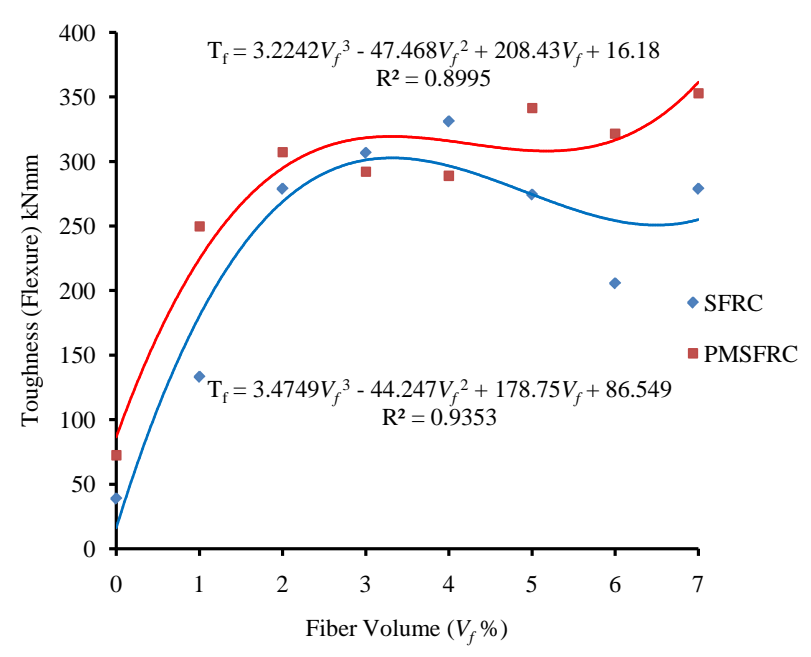

Figure 14. Variation of flexural toughness $\left(T_{f}\right)$ with respect to fiber content $\left(V_{f}\right)$.

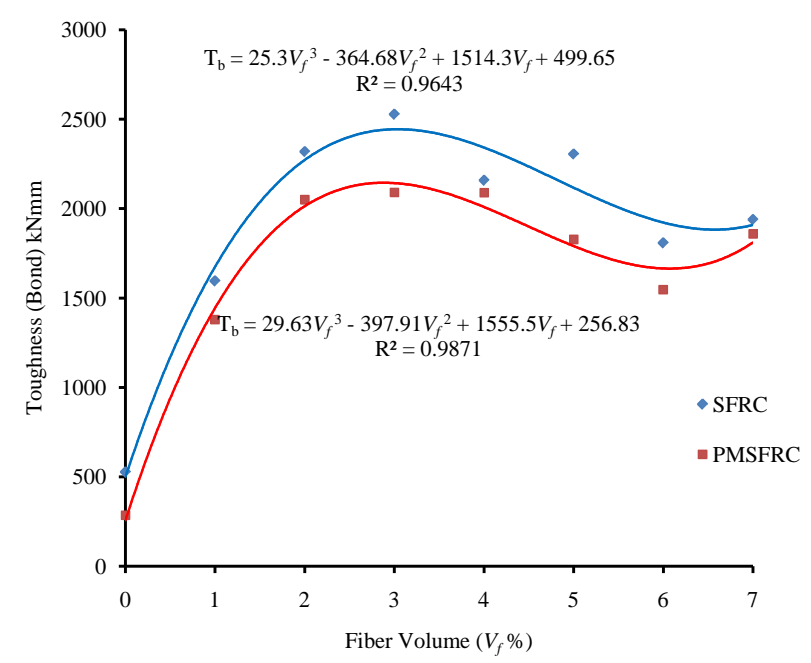

Figure 15. Variation of bond toughness $\left(T_{b}\right)$ with respect to fiber content $\left(V_{f}\right)$.

\section{Conclusions}

An experimental study of toughness of PMSFRC has been presented in this study. On the basis of results obtained from this experimental investigation, following conclusions are drawn.

- It is observed that the strain softening, which is an increase in strain under constant load, is evident in inelastic range in compression. The elastic strain capacity increased with the increase in fiber volume fraction. The maximum compression toughness is observed at $1 \%$ of fiber content.

- The addition of fibers and polymer increased the flexural toughness at $7 \%$ of fiber content.

- The maximum toughness under bond strength is observed at $3 \%$ of fiber content.

In general it is observed that fibers and polymer are very effective in improving toughness of concrete composites.

\section{References}

[1] Kuder, K.G., Ozyurt, N., Mu, E.B. and Shah, S.P. (2007) Rheology of Fiber Reinforced Cementitious Materials. Cement and Concrete Research, 37, 191-199. http://dx.doi.org/10.1016/j.cemconres.2006.10.015

[2] Balaguru, P. and Najm, H. (2004) High-Performance Fiber-Reinforced Concrete Mixture Proportions with High Fiber 
Volume Fractions. ACI Materials Journal, 101, 281-286.

[3] Balguru, P. and Shah, S.P. (1992) Fiber Reinforced Cement Composites. McGraw-Hill, Inc., New York, 1-531.

[4] Mallick, P.K. (1946) Fiber-Reinforced Composites, Materials, Manufacturing, and Design. Marcel Dekker, Inc., New York, 1-566.

[5] Beaudoin, J.J. (1990) Handbook of Fiber-Reinforced Concrete (Principles, Properties, Developments and Applications). Noyes Publications, Park Ridge, USA, 1-332.

[6] Banthia, N. and Bindiganavile, V. (2007) Fiber Reinforced Shotcrete. Concrete International, 29, 53-58.

[7] Topeu, I.B. and Canbaz, M. (2007) Effect of Different Fibers on the Mechanical Properties of Concrete Containing Fly Ash. Construction and Building Materials, 21, 1486-1491. http://dx.doi.org/10.1016/j.conbuildmat.2006.06.026

[8] Mirsayah, A.A. and Banthia, N. (2002) Shear Strength of Steel Fiber Reinforced Concrete. ACI Materials Journal, 99, 473-479.

[9] Nehdi, M and Ladanchuk, J.D. (2004) Fiber Synergy in Fiber-Reinforced Self Consolidating Concrete. ACI Materials Journal, 101, 508-517.

[10] Dupont, D. and Vandewalle, L. (2005) Distribution of Steel Fibers in Rectangular Sections. Cement and Concrete Composites, 27, 391-398. http://dx.doi.org/10.1016/j.cemconcomp.2004.03.005

[11] Altun, F., Haktanir, T. and Ari, K. (2007) Effects of Steel Fiber Addition on Mechanical Properties of Concrete and RC Beams. Construction and Building Materials, 21, 654-661. http://dx.doi.org/10.1016/j.conbuildmat.2005.12.006

[12] Taylor, M.R., Lydon, F.D. and Barr, B.I.G. (1997) Toughness Measurement on Steel Fibre Reinforced High Strength Concrete. Cement and Concrete Composites, 19, 329-340. 